\title{
Adsorption of Naphthalene on Clay and Sandy Soil from Aqueous Solution
}

\author{
Ebuwa I. Osagie, Chiedu N. Owabor \\ School of Energy, Environment and Agri-Food, Cranfield University, Bedfordshire, UK \\ Email: e.i.osagie@cranfield.ac.uk
}

Received 19 June 2015; accepted 10 July 2015; published 13 July 2015

Copyright (C) 2015 by authors and Scientific Research Publishing Inc.

This work is licensed under the Creative Commons Attribution International License (CC BY). http://creativecommons.org/licenses/by/4.0/

(c) (i) Open Access

\begin{abstract}
The adsorption behavior of naphthalene using clay and sandy soil as adsorbents is examined under ambient conditions. The adsorption equilibrium of naphthalene on clay and sandy soil was evaluated by the Langmuir, Freundlich and Tempkin isotherms. The results showed that the equilibrium data for naphthalene fitted the Freundlich model best within the concentration range studied for both clay and sandy soil. Experimental results showed that the time taken to attain adsorption equilibrium for naphthalene was $26 \mathrm{hrs}$ and $20 \mathrm{hrs}$ for clay and sandy soil, respectively. Among the tested kinetic models in this study, the pseudo-second order successfully predicted the adsorption process.
\end{abstract}

\section{Keywords}

Adsorption, Naphthalene, Kinetic Models, Equilibrium, Isotherms, Clay, Sandy Soil

\section{Introduction}

Various toxic chemicals such as polycyclic aromatic hydrocarbons (PAHs) including naphthalene, anthracene, benzo (a) pyrene, phenanthrene, benzene, toluene, ethyl benzene and xylene (BTEX), heavy metals and dyes are continuously discharged into the environment as industrial waste, causing water, air and soil pollutants. These chemicals are recalcitrant and persistent in nature and have low solubility in water but highly lipophilic. Polycyclic aromatic hydrocarbons (PAHs) occur naturally in petroleum oil, coal and the burning of fuel. The activities of paper mills also release these compounds to the environment. PAHs constitute an important class of highly toxic and long persistent environmental pollutants. Most PAHs are hydrophobic with high boiling and melting points and possess low water solubility and electrochemical stability. Therefore, they can exist and be accumulated in the environmental for long times [1]. In recognition of their toxicity and high mobility, the World Health Organization (WHO) has recommended a limit for PAH in drinking water [2]. The European En- 
vironmental Agency (EEA) has also included these compounds in its list of priority pollutants to be monitored in industrial effluents [3]. They have been identified in a variety of waters and wastewaters since they are associated with a number of industrial sources such as incomplete fuel combustion and coke making [4]. Faced with an increasing contamination of water resources, adsorption technology has become widely used in water treatment plants since it is a well-established and powerful technique due to its high depuration efficiency [5]. Adsorption is a physical separation process in which certain compounds of a fluid phase are transferred to the surface of a solid adsorbent as a result of the influence of Van der Waals forces [6]. Compared with other PAHs species, naphthalene is the simplest PAH; it has less toxicity and is easily found in the environment [1]. The adsorption of naphthalene in this study will provide useful information for the treatment of naphthalene and also can be viewed as the primary method of inquiry for dealing with more complicated PAHs.

The aim of this study is to investigate the feasibility of using clay and sandy soil to remove naphthalene from aqueous solution. The abundance of clay in most continents of the world and its low cost make it a strong candidate as an adsorbent for the removal of many pollutants from wastewaters [7]. The capacity of these materials for the removal of naphthalene, one of the most abundant polycyclic aromatic compounds in wastewater from aqueous solution is evaluated. The adsorption of naphthalene on clay and sandy soil is further evaluated by the common isotherms (e.g. Langmuir, Freundlich and linear isotherms) and kinetic models (e.g. pseudo-first order and pseudo-second order) rate equations.

\section{Materials and Methods}

\subsection{Materials}

The clay and sandy soil used in this study were obtained from Ikpoba River, Benin City, Edo State, Nigeria. After collection, the materials were stored in a black polythene bag. Stones and other heavy particles were removed from the materials. A $220 \mu \mathrm{m}$ mesh was used to remove the large non-clay fractions from the clay and a $2.5 \mathrm{~mm}$ mesh was used to sieve the sandy soil. Then they were dried overnight at $343^{\circ} \mathrm{K}$ in a vacuum oven and stored in an air-tight container covered with a black polythene bag prior to the adsorption experiments.

The adsorbate, naphthalene was bought from a chemical laboratory in Benin City. The distilled water used for sample preparation, dilution and solution was obtained from the Department of Chemical Engineering, University of Benin, Benin City, Edo State, Nigeria.

\subsection{Methods}

\subsubsection{Adsorption Kinetics Experiments}

The rates of adsorption by the absorbents clay and sandy soil were determined from the uptake levels of naphthalene from aqueous solution in batch experiments before and after contact until equilibrium was attained in the clay and sandy soil. $100 \mathrm{~g}$ of each of the absorbents (clay and sandy soil) was mixed with $500 \mathrm{ml}$ of aqueous solution of the adsorbates at room temperature. The slurry suspensions were sampled at intervals of 2 hours and UV spectrophotometer was used for sample analysis.

\subsubsection{Adsorption Kinetics Models}

The adsorption kinetics which describes the mechanism of the adsorption process in a given system were determined in this study using pseudo-first order model as defined by [8] and pseudo-second order model [9].

\section{Results and Discussion}

The results of the experimentation and computation analysis of the kinetic modeling of the adsorption of naphthalene onto clay and sandy soil are presented. The potential of the two adsorbents to adsorb the contaminant solutes has been exploited. The analysis of the predictions from the kinetic modeling data obtained from the experiments provided the basis for the choice of the applicable and suitable mechanism for describing the adsorption process.

\subsection{Effect of Varying Concentration on the Adsorption of Naphthalene}

The effect of the variation of concentration of naphthalene in the effluent solution is described by using the Langmuir, Freundlich and Tempkin Isotherm models. These isotherms are graphically represented below. 
Figures 1-6 show that the equilibrium concentration and the amount of naphthalene adsorbed increased as the initial effluent concentration increased. The Langmuir, Freundlich and Tempkin Isotherm constants were calculated from the slope and intercepts of the graphs. The Freundlich Isotherm plot in Figure 3 gave the best linear plot with a correlation coefficient $\left(\mathrm{R}^{2}=0.9647\right)$ for naphthalene sorption with clay. The Langmuir isotherm plot in Figure 4 gave the best linear plot with a correlation coefficient $\left(\mathrm{R}^{2}=0.8602\right)$ for naphthalene sorption with sandy soil. The experimental data for this work best fits the Freundlich model. This result agrees with the work of [10] in which clay adsorbent was also used. The adsorption capacity Qo (mg/g) and energy of adsorption $\mathrm{n}$ for naphthalene were 5.734 and 0.0107 , respectively.

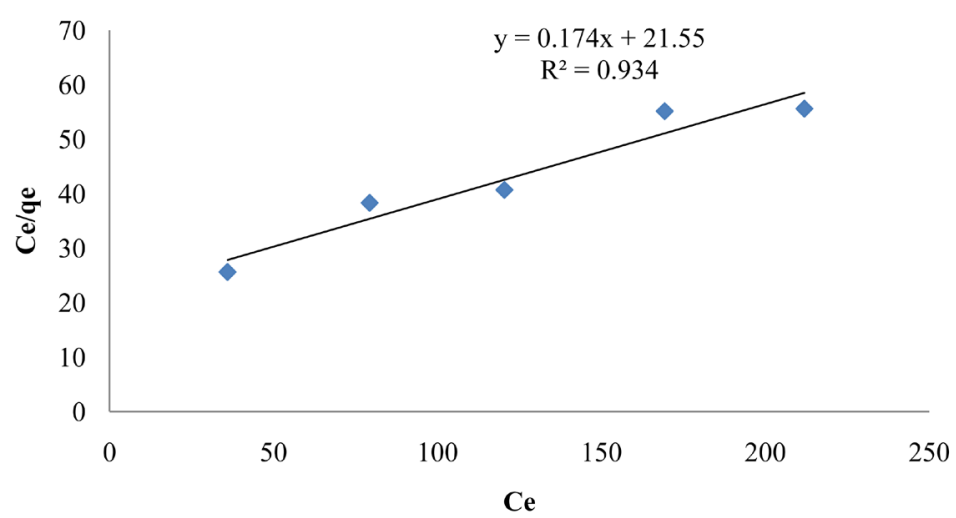

Figure 1. Langmuir plot for the variation of concentration for naphthalene sorption with clay.

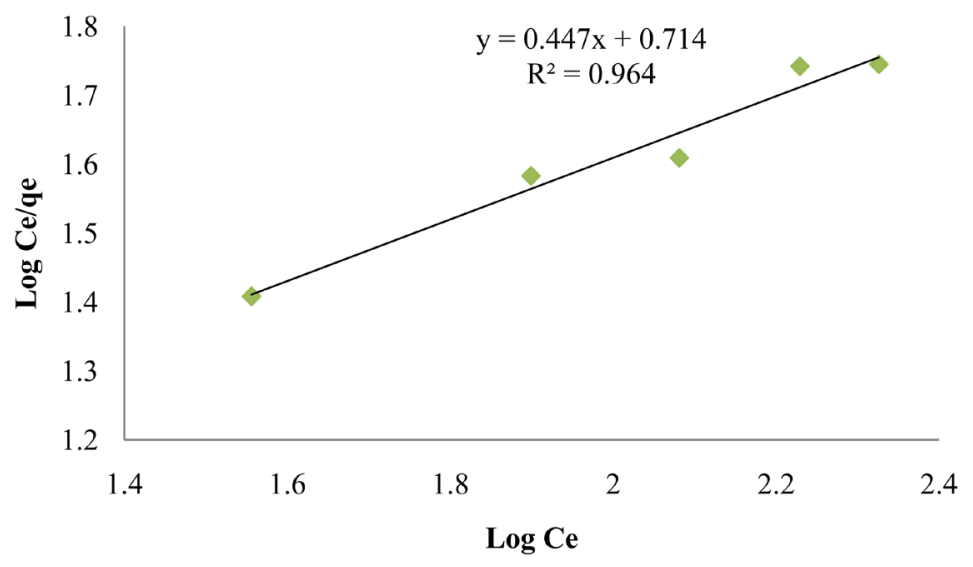

Figure 2. Freundlich plot for the variation of the concentration of naphthalene sorption with clay.

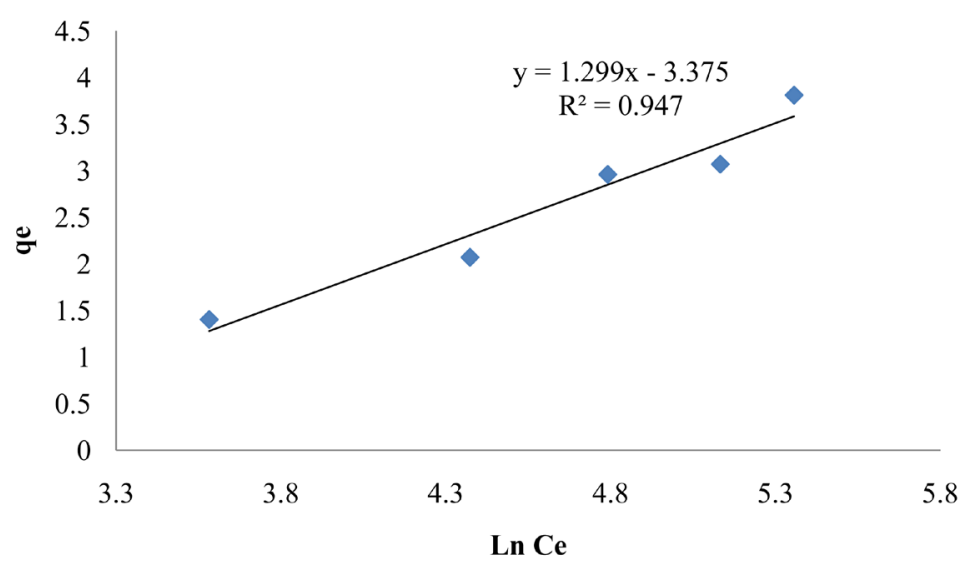

Figure 3. Tempkin plot for the variation of the concentration of naphthalene sorption with clay. 


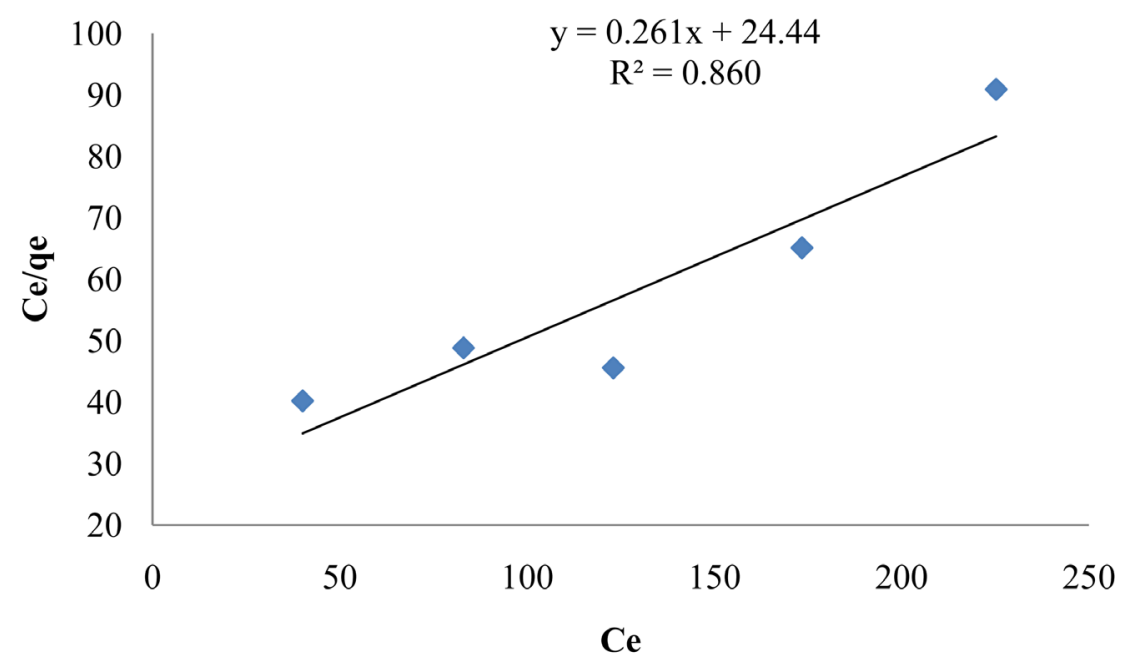

Figure 4. Langmuir plot for the variation of the concentration of naphthalene sorption with sandy soil.

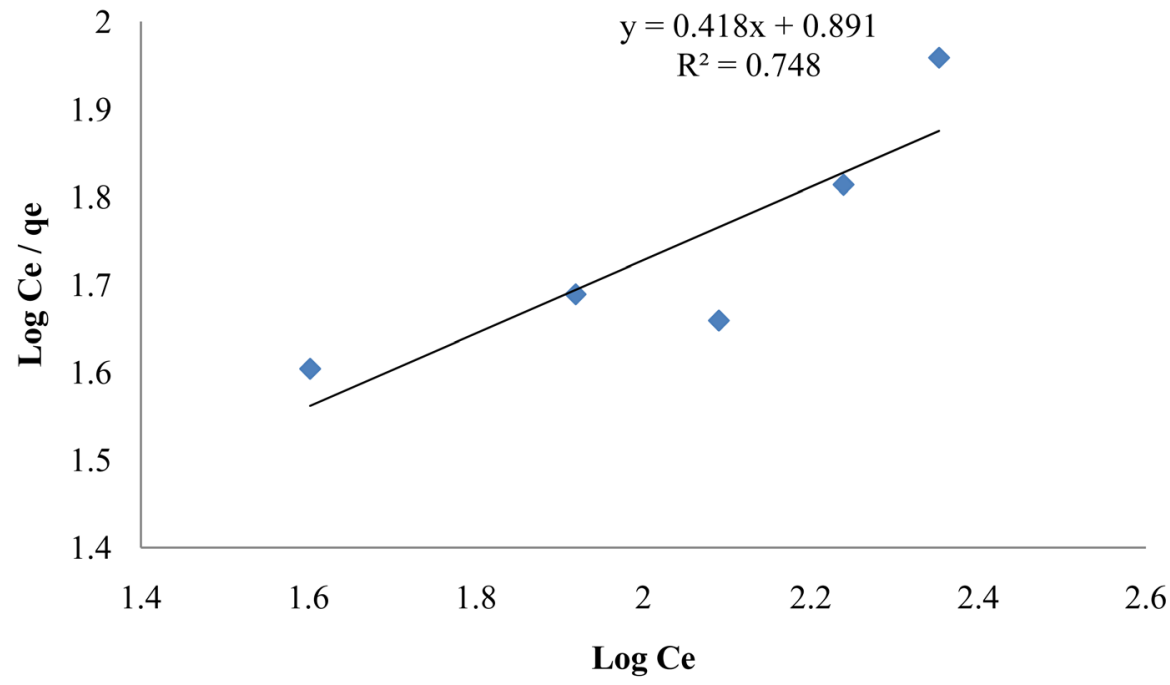

Figure 5. Freundlich plot for the variation of the concentration of naphthalene sorption with sandy soil.

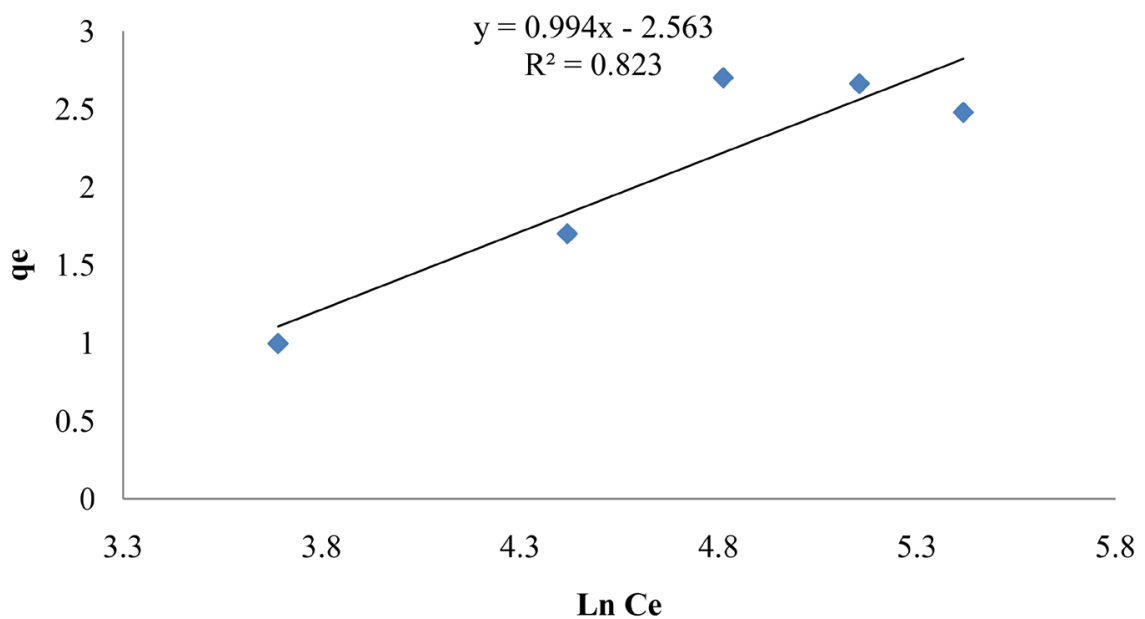

Figure 6. Tempkin plot for the variation of the concentration of naphthalene sorption with sandy soil. 


\subsection{Equilibrium Time and Agitation Time for Adsorption of Naphthalene}

From Figure 7, the adsorption results showed that equilibrium was achieved in 26 and 20 hrs for naphthalene in clay and sandy soil, respectively. From the equilibrium time, sandy soil was observed to reach equilibrium faster than clay for naphthalene used in this study. This can be attributed to the large pore spaces, intra-porous nature and the high permeability of sandy soil. Figure 7 also indicates that there was a steady adsorption of naphthalene by the two different adsorbent.

The effect of agitation time on the adsorption of naphthalene is shown in Figure 8. It shows that agitation time has an effect on the adsorption of naphthalene from an aqueous solution. The amount of naphthalene adsorbed increased as the agitation time increases until an equilibrium time was reached beyond which the amount of naphthalene removed becomes negligible and in the long run becomes constant. The sharp decrease in the curve for both clay and sandy soils indicates that significant adsorption is taking place at that particular time. The removal of naphthalene is rapid in the initial stages of agitation time and gradually decreases with the lapse of time until saturation. The removal curve is single, smooth and continuous indicating monolayer coverage of naphthalene on the outer surface of the adsorbent [9].

\subsection{Sorption Kinetics}

Table 1 shows the results of the kinetic modeling of the adsorption of naphthalene onto clay and sandy soil used in this study. Comparing the values of the correlation coefficients $\mathrm{R}^{2}$ of pseudo-first order and second order eq-

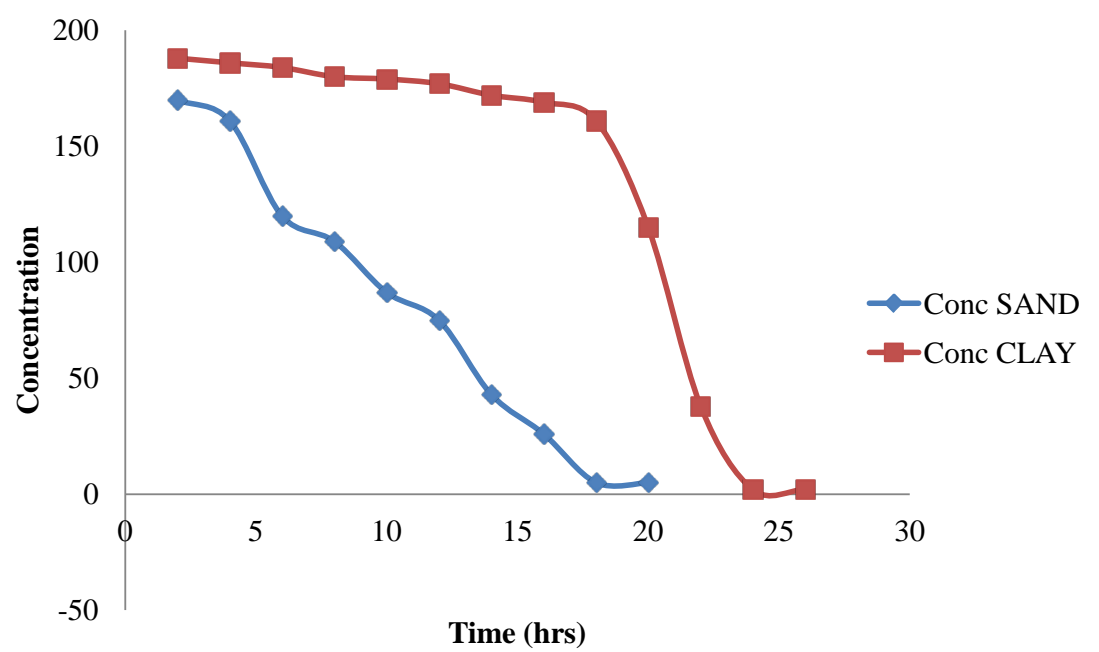

Figure 7. Variation of concentration with time for naphthalene sorption in clay and sandy soil.

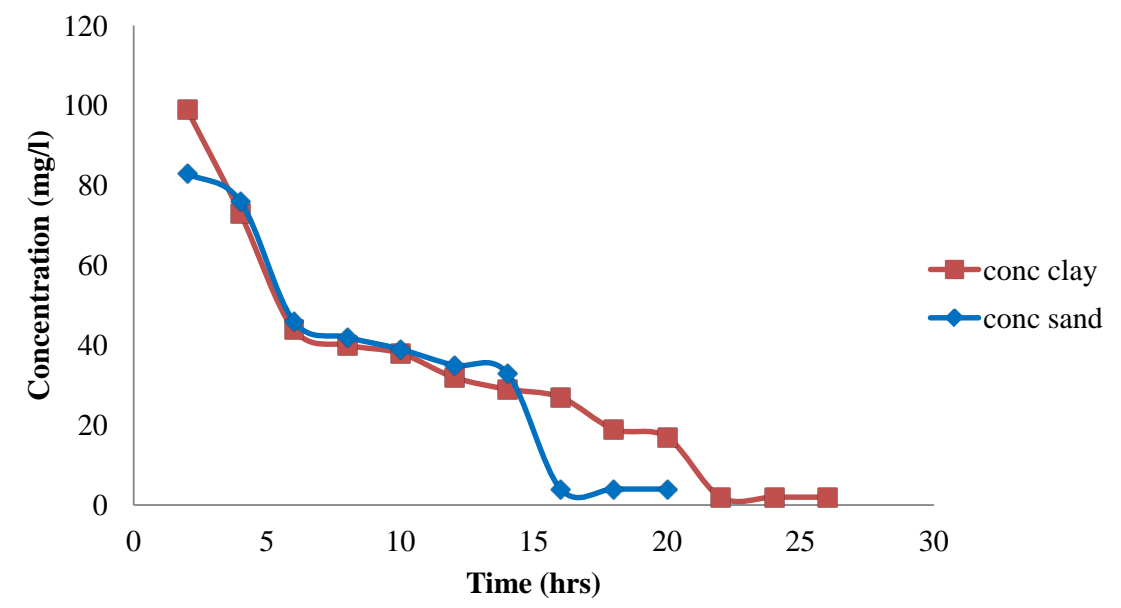

Figure 8. The effect of agitation time on the adsorption of naphthalene. 
Table 1. Kinetic parameters and correlation coefficient $\left(\mathrm{R}^{2}\right)$ values for the adsorption of naphthalene using clay and sandy soil.

\begin{tabular}{cccc}
\hline Kinetic Model & Parameters & Clay & Sandy Soil \\
\hline Pseudo-First Model & $\mathrm{k}_{1}$ & 0.0723 & 0.9084 \\
& $\mathrm{q}_{\mathrm{e}}$ & 40.29 & 37.74 \\
& $\mathrm{R}^{2}$ & 0.0723 & 0.9084 \\
Pseudo-Second Model & $\mathrm{k}_{2}$ & 0.00069 & 0.00023 \\
& $\mathrm{Q}_{\mathrm{e}}$ & 39.84 & 19.92 \\
& $\mathrm{R}^{2}$ & 0.1442 & 0.9039 \\
\hline
\end{tabular}

uations, the latter is better than the former and can be used to predict the adsorption kinetics of naphthalene on clay and sandy soil. The value of the reaction rate constant $\mathrm{k}_{1}$ predicted for the adsorption kinetics by the pseudo-first order was found to be ambiguous. The amount of naphthalene adsorbed in the clay sample before equilibrium was $39.84 \mathrm{mg}$ while in the sandy soil, the amount was $19.92 \mathrm{mg}$. Based on the amount adsorbed, given equal times before equilibrium, clay could be described as a better adsorbing agent of naphthalene than sandy soil. This property of clay over sandy soil can be attributed to its larger surface area and higher porosity than sandy soil [11]. Sand has low porosity though not as many pore spaces because the grains are very large such that in a unit of sand, the fraction of soil volume that consists of holes is a lot less than for clay. Clay has many small pore spaces in which water containing the contaminant solutes remains clinging to the clay particle surfaces. Porosity is an important consideration when evaluating the potential volume of water or amount of hydrocarbons sediments may contain. Sediments with higher porosity typically have higher hydraulic conductivity, a property of sediments that describes the ease with which water can move through pore spaces [12].

\section{Conclusion}

The study showed that the adsorption of PAHS (naphthalene) occurred in clay and sandy soil with clay adsorbing more of the naphthalene than sandy soil. The adsorptive property of clay over sandy soil was attributed to its large surface area, higher porosity and high hydraulic conductivity of the adsorbates. For the adsorption process, equilibrium was attained faster for sandy soil than for clay as a result of the higher permeability of sandy soil. The sorption process was found to follow the pseudo-second order mechanism.

\section{Acknowledgements}

The authors acknowledge the financial support for this work from the Vice-Chancellor, University of Benin and the Federal Government Scholarship program.

\section{References}

[1] Chang, C., Chang, C., Chen, K., Tsai, W., Shie, J. and Chen, Y. (2004) Adsorption of Naphthalene on Zeolite from Aqueous Solution. Journal of Colloid and Interface Science, 277, 29-34. http://dx.doi.org/10.1016/j.jcis.2004.04.022

[2] World Health Organization (2009) Nitrobenzene in Drinking-Water: Background Document for Development of WHO Guidelines for Drinking-Water Quality.

[3] WFD, E. (2000) Directive 2000/60/EC of the European Parliament and of the Council Establishing a Framework for the Community Action in the Field of Water Policy. Joint Text Approved by the Conciliation Committee Provided for in Article, 251.

[4] Williams, P. (1990) Sampling and Analysis of Polycyclic Aromatic Compounds from Combustion Systems: A Review. Journal of the Institute of Energy, 63, 22-30.

[5] Bandosz, T.J. (2006) Activated Carbon Surfaces in Environmental Remediation. Academic Press, Waltham.

[6] McCabe, W.L., Smith, J.C. and Harriott, P. (1993) Unit Operations of Chemical Engineering. McGraw-Hill, New York.

[7] Koh, S. and Dixon, J.B. (2001) Preparation and Application of Organo-Minerals as Sorbents of Phenol, Benzene and 
Toluene. Applied Clay Science, 18, 111-122. http://dx.doi.org/10.1016/S0169-1317(00)00040-5

[8] Lagergren, S. (1898) About the Theory of So-Called Adsorption of Soluble Substances.

[9] Sivraj, R., Namasivayam, C. and Kadirvelu, K. (2001) Orange Peel as an Adsorbent in the Removal of Acid Violet 17 (Acid Dye) from Aqueous Solution. Waste Manage, 21, 105-110. http://dx.doi.org/10.1016/S0956-053X(00)00076-3

[10] Treybal, R.E., Rodríguez, A.G. and Lozano, F.J. (1980) Operaciones de transferencia de masa. McGraw-Hill, New York.

[11] Curry, C.W., Bennett, R.H., Hulbert, M.H., Curry, K.J. and Faas, R.W. (2004) Comparative Study of Sand Porosity and a Technique for Determining Porosity of Undisturbed Marine Sediment. Marine Georesources and Geotechnology, 22, 231-252. http://dx.doi.org/10.1080/10641190490900844

[12] Huang, W., Peng, P., Yu, Z. and Fu, J. (2003) Effects of Organic Matter Heterogeneity on Sorption and Desorption of Organic Contaminants by Soils and Sediments. Applied Geochemistry, 18, 955-972. http://dx.doi.org/10.1016/S0883-2927(02)00205-6 